\title{
Pesquisa-ação: concepções e aplicabilidade nos estudos em Enfermagem
}

\author{
Action research: concepts and applicability in Nursing studies \\ Investigación-acción: conceptos y aplicación en los estudios de Enfermería
}

\section{Jaqueline Carvalho e Silva', Eronice Ribeiro de Morais", Maria do Livramento Fortes Figueiredo"', Maria Antonieta Rúbio Tyrrelliv}

\author{
'Estratégia Saúde da Família. Teresina-PI, Brasil. \\ "Faculdade Integral Diferencial. Teresina-Pl, Brasil. \\ III Universidade Federal do Piauí. Departamento de Enfermagem. Teresina-PI, Brasil. \\ iv Universidade Federal do Rio de Janeiro. Escola de Enfermagem Anna Nery. Rio de Janeiro-RJ, Brasil.
}

\section{RESUMO}

Esta é uma reflexão teórica sobre a pesquisa-ação e suas contribuições como abordagem metodológica para a ampliação da produção de conhecimentos em Enfermagem. Além das concepções teóricas de vários autores sobre esta metodologia, levantou-se, na produção científica de Enfermagem, a aplicabilidade da pesquisa-ação nas investigações na área. Observouse que este método permite uma interação entre o pesquisador e o pesquisado, relação esta que já é estabelecida na prática cotidiana das atividades desenvolvidas pelo enfermeiro, visto que o mesmo permite que os sujeitos (clientes) tenham voz e vez, ou seja, permite um diálogo aberto, participativo e reflexivo, assistindo-o de forma holística, incluindo-o sempre em um conjunto com sua família e comunidade, além de buscar constantemente a transformação positiva dessa realidade.

Descritores: Metodologia; Pesquisa; Enfermagem.

\section{ABSTRACT}

This is a theoretical reflection on action-research and its contributions as a methodological approach to the expansion of knowledge production in Nursing. Besides the theoretical concepts of several authors on this methodology, we tried to identify, in the scientific production of Nursing, the applicability of the action-research in the investigations of the area. We observed that this method allows an interaction between the researcher and the object being researched, a relationship which is already established in the daily practice of the activities undertaken by nurses, because it allows the subjects (clients) to have voice and opportunity. In other words, it allows a dialogue which is open, participatory and reflective, assisting the individuals from a holistic point of view, always including them in an interaction with their families and the community, in addition to constantly seeking a positive transformation of this reality.

Key words: Methodology; Nursing; Research.

\section{RESUMÉN}

Esta es una reflexión teórica sobre la investigación-acción y sus contribuciones como enfoque metodológico para la ampliación de la producción del conocimiento en Enfermería. Además de las concepciones teóricas de varios autores acerca de esta metodología, se plantea en la producción científica de enfermería la aplicabilidad de la investigación-acción en las investigaciones en esta área. Fue observado que este método permite una interacción entre el investigador y el investigado, relación esta que ya está establecida en la práctica diaria de las actividades desarrolladas por los enfermeros, porque permite que los sujetos (los clientes) tengan voz y vez, es decir, permite un diálogo abierto, participativo y reflexivo, asistiéndolo de modo integral, incluyéndolo siempre en conjunto con su familia y la comunidad, además de la constante búsqueda de una transformación positiva de esa realidad.

Palabras clave: Metodología; Investigación; Enfermería. 


\section{INTRODUÇÃO}

A escolha correta da metodologia caracteriza o caminho e a prática a ser seguida pelo pesquisador na abordagem da realidade, inclui o método, as técnicas, além da criatividade do investigador, portanto, ocupa espaço central no interior das teorias sociais. Assim, a escolha do caminho metodológico mostra a intencionalidade do pesquisador sobre um determinado fenômeno ${ }^{(1)}$.

A Enfermagem, para obter respostas e resultados a seus questionamentos e inquietações, vem realizando vários estudos e pesquisas que diretamente têm contribuído para a ampliação e a produção de conhecimentos em saúde. Entretanto, a Enfermagem como ciência deve ter uma visão holística do ser humano e, assim, entender que o mesmo possui diferenças culturais e comportamentais, sentimentos próprios de cada ser, preferências sexuais, tabus, mitos e preconceitos. Desta forma, vem utilizando as pesquisas qualitativas para estudar e desvendar a subjetividade dos fenômenos humanos.

A pesquisa qualitativa estuda os aspectos dos cenários naturais, não se limitando a dados isolados ligados a uma teoria, o sujeito faz parte do processo de conhecimento interpretando os fenômenos. Por isso esta abordagem ainda permite explorar todas as dimensões da singularidade do ser humano, possibilitando a compreensão do fenômeno estudado para o sujeito da pesquisa ${ }^{(2)}$. Muitos são os caminhos metodológicos na pesquisa qualitativa que podem ser seguidos por um pesquisador para o alcance dos resultados dos seus questionamentos e inquietações, porém dentre eles destaca-se a metodologia da pesquisa-ação.

A metodologia da pesquisa-ação tem suas origens nos trabalhos de Kurt Lewin, em 1946, num contexto pós-guerra, quando o mesmo trabalhava com o governo norte-americano e desenvolvia atividades relacionadas a mudanças de hábitos alimentares e mudanças de atitudes desses americanos frente a outros grupos minoritários. Seus trabalhos eram desenvolvidos paralelamente aos seus estudos sobre o desenvolvimento e funcionamento de grupos. Daí o fato da pesquisa-ação, naquele momento, ser bastante aceita e desenvolvida nas empresas que exerciam atividades ligadas ao desenvolvimento organizacional ${ }^{(3)}$.

Esta concepção de reflexão para a mudança, visando meIhorar o trabalho e o desenvolvimento organizacional, foi substituída nos anos de 1946 a 1948, a partir de influencias das linhas positivistas, que modificaram a concepção de pesquisa-ação anteriormente cultivada por Lewin, passando a ser fragmentada em quatro tipos: diagnóstica, participante, empírica e experimental. Faz-se necessário enfatizarmos que tais dimensões sempre estiveram presentes, de forma integrada, nos estudos de Lewin; e que estas mudanças levaram ao enfraquecimento e ao desconhecimento das reais origens desta metodologia por parte de alguns pesquisadores ${ }^{(3)}$.

Porém, a utilização da metodologia da pesquisa-ação vem crescendo atualmente, sendo utilizada de diferentes maneiras, a partir de diversas intencionalidades, destacando o seu emprego nos campos da educação, comunicação (publicidade e propaganda), serviço social, organização e sistemas, desenvolvimento rural (agronomia), difusão de tecnologia, área bancária, práticas políticas e pela saúde, em destaque pela Enfermagem ${ }^{(4)}$.

Entende-se a pesquisa-ação como "uma linha de pesquisa associada a diversas formas de ação coletiva que é orientada em função da resolução de problemas ou de objetos de transformação"(5). Ou seja, entende-se que é uma forma de pesquisa que se propõe a realizar uma ação coletivamente. Nessa perspectiva, pode-se observar a importância desta metodologia tanto para pesquisas na área da Enfermagem quanto para as realizadas em Saúde Pública, tendo em vista que as pesquisas desenvolvidas nessas duas áreas têm por fim a ação do cuidar, a promoção do bem-estar e melhoria na qualidade de vida da população.

À luz desse contexto, podem-se destacar os Programas de Saúde Coletiva, dentre eles a Estratégia Saúde da Família (ESF), como um espaço privilegiado para a utilização da metodologia da pesquisa-ação, tendo em vista que este local propicia a construção social do conhecimento por meio da participação dos atores envolvidos nesse processo de mudança e transformação de suas realidades, além do fato dos profissionais, em destaque o enfermeiro, possuírem uma interação com os sujeitos da comunidade ${ }^{(6)}$.

Entretanto, muitos pesquisadores receiam a utilização da metodologia da pesquisa-ação, referindo que as pesquisas que utilizam esta abordagem são menos científicas e mais expostas a manipulações por parte de seus pesquisadores do que as pesquisas convencionais. Cabe aos pesquisadores que utilizam tal abordagem valerem-se também da ética em pesquisa e do controle rigoroso do método, pois a utilização desse tipo de abordagem metodológica tem efeito significativo na trajetória de vida dos grupos envolvidos na pesquisa ${ }^{(4-5)}$.

Tendo em vista os aspectos abordados, este estudo objetiva refletir sobre a metodologia da pesquisa-ação, bem como suas contribuições como abordagem metodológica para a produção e ampliação do conhecimento em Enfermagem.

\section{DISCUTINDO A METODOLOGIA DA PESQUISA- AÇÃO E SUA APLICABILIDADE NOS ESTUDOS EM ENFERMAGEM}

A escolha metodológica da pesquisa-ação se mostra apropriada como caminho para desvendar um fenômeno social de base empírica; e como método de pesquisa social que estabelece uma relação com a estrutura coletiva, além de ser participativa e ativa ao nível da capacitação de informações ${ }^{(5,7)}$.

Ao ser utilizada esta opção metodológica, pode-se evidenciar a sua flexibilidade como método participativo de investigação, pois ele mostra-se como uma metodologia que possibilita a interação entre pesquisador e sujeitos da pesquisa, ou seja, entre o saber formal e saber informal, entre a teoria e a prática, conduzindo a mudanças reais na forma como as pessoas interagem entre si e com os outros ${ }^{(8)}$.

Comparando-se esta metodologia com as demais, pode-se destacar que a pesquisa-ação configura-se até 6,7 mais diff́cil do que as pesquisas convencionais, não sendo simples, nem fácil, como citado por alguns pesquisadores. Porém, a 
utilização deste método é bastante gratificante, pois permite que o sujeito da pesquisa se envolva com seus problemas, aumentando a probabilidade dos achados da pesquisa se transformar em ação ${ }^{(9)}$.

Nesse sentido, ao optar por essa metodologia, deve-se ter em mente a necessidade de uma interação ou cooperação do pesquisador com os participantes, tendo em vista, que esse tipo de metodologia estabelece uma relação participativa e ativa com o coletivo como anteriormente citado. Além disso, é importante destacar o tempo que será utilizado para o cumprimento de todas as etapas desse método, visto que este possui doze etapas que devem ser seguidas pelo pesquisador ${ }^{(6)}$.

Outro ponto que merece destaque refere-se à característica exploratória da ação, o senso ético que deve ser sempre preservado pelo pesquisador, a não imposição de valores ou grandes expectativas nos participantes da pesquisa, a atenção e o respeito às características próprias de cada pessoa, o tempo necessário para adquirir confiança dos sujeitos no pesquisador, além da adoção de um ambiente harmonioso e fraterno, buscando sempre um bom acolhimento e o bem-estar desses participantes ${ }^{(10)}$.

Ao serem observados todos esses pontos, destacamos o enfermeiro-pesquisador como um ser capaz de seguir e cumprir todos os requisitos desse método de pesquisa, tendo em vista, que tais atividades já são desenvolvidas no cotidiano de seu trabalho e muitas vezes são realizadas até de forma espontânea, assim, cabe a este profissional mostrar que é possível unir teoria a prática, numa relação de contínuo crescimento e reconhecimento de seu trabalho ${ }^{(4)}$.

Como exemplo da viabilidade da utilização deste método, destaca-se na produção científica em Enfermagem no Piauí a tese de Doutorado intitulada "A mulher idosa e a educação em saúde: saberes e práticas para a promoção do envelhecimento saudável" defendida em 2005 através do Programa de Qualificação Institucional da CAPES realizado na Escola de Enfermagem Anna Nery (EEAN) da Universidade Federal do Rio de Janeiro (UFRJ); e, na atualidade, o desenvolvimento do Projeto de Dissertação de Mestrado "A percepção da mulher idosa sobre sua sexualidade" no Programa de Pós-Graduação Mestrado em Enfermagem, da Universidade Federal do Piauí (UFPI).

Em ambos os estudos a opção por esta metodologia deveu-se à flexibilidade, uma forte interação entre os sujeitos e a pesquisadora e possibilidade de participação dos sujeitos da investigação. Além do mais os objetos de estudo delimitados são fenômenos subjetivos e repletos de saberes, experiências, mitos, tabus e preconceitos que certamente emergiram e emergirão com maior facilidade nas expressões grupais, próprias da técnica mais utilizada na pesquisa-ação que é o seminário. Assim sendo, identifica-se na pesquisa-ação uma ação dialógica critica e reflexiva permitindo dar voz, vez e oportunidade de expressão a esses sujeitos, respondendo os objetivos proposto no estudo ${ }^{(6)}$.

A metodologia da pesquisa-ação possui doze fases que se interrelacionam e que são flexíveis, ou seja, não necessitam ser seguidas de forma ordenada e com rigidez. A seguir descrevem-se essas etapas, de forma resumida e ordenada, tendo em vista que, para o entendimento completo desse método de pesquisa, é necessário um estudo mais detalhado e minucioso por parte do pesquisador que deseja utilizá-lo ${ }^{(5)}$.

1. Fase exploratória: como o próprio nome sugere, é uma fase em que será explorado o campo de pesquisa, seus possíveis interessados, suas ações, além de ser realizado o levantamento da situação, dos problemas prioritários e elaborado os objetivos da investigação.

2. O tema da pesquisa: deve ser elaborado de forma simples; entretanto deve sugerir os problemas e o enfoque que será abordado. Este deve ainda ser de interesse dos participantes e dos pesquisadores, para que haja cooperação e interesse mútuo.

3. A colocação dos problemas: definição do problema no qual o tema e os objetivos adquirem sentido, ou seja, devem ser colocados os problemas que se pretende resolver dentro de um campo teórico e prático.

4. O lugar da teoria: a teoria surge para fornecer sustentação aos achados na metodologia da pesquisa-ação. Esta deve ser trazida para as discussões permitindo o entendimento por parte de todo o grupo.

5. Hipóteses: estas são conceituadas como uma suposição formulada pelo pesquisador para o problema de pesquisa, tendo em vista suas possíveis soluções.

6. Seminário: este se constitui como a principal técnica para coletar os dados, pois centraliza todas as informações coletadas em outros momentos e depois discute suas interpretações. Posteriormente são confeccionadas as Atas de cada seminário.

7. Campo de observação, amostragem e representatividade qualitativa: na pesquisa-ação este campo observacional pode abranger geograficamente uma comunidade concentrada ou espalhada, já em relação à amostragem e representatividade qualitativa estas são discutíveis.

8. Coleta de dados: esta é efetuada de várias formas, através das técnicas de entrevistas coletivas, entrevistas individuais com profundidade, questionários, observação participante, diário de campo, além da história de vida, entretanto, todas essas técnicas ficam sob controle do seminário central.

9. Aprendizagem: esta etapa envolve a produção e circulação de informações, elucidação e tomada de decisões, além de outros aspectos que fornecerá mais aprendizado aos participantes. Através da pesquisa-ação, tanto pesquisador quanto os participantes, aprendem ao investigar e discutir suas ações.

10. Saber formal/saber informal: visam estabelecer a comunicação, o entendimento e a relação entre os dois universos culturais: os dos especialistas e dos participantes, tendo em vista que os dois sempre terão algo a contribuir um com o outro.

11. Plano de ação: é uma exigência da pesquisa-ação, deve se concretizar em uma ação planejada entre o pesquisador e os participantes. O plano de ação objetiva a ação que precisa ser realizada para a obtenção da solução de um problema existente. 
12. Divulgação externa: pode ser realizada em dois momentos: primeiramente deve ser realizado o retorno dos resultados da pesquisa ao grupo de participantes do estudo e posteriormente devem ser discutidas e planejadas diferentes formas de divulgação externa, através de congressos, seminários, periódicos, dentre outros.

Após a análise dessas fases, faz-se necessário relembrarmos que elas se interrelacionam e que são bastante flexíveis, mas deve-se ter em mente também que elas representam um ponto de partida e de chegada deste método, e que sempre o pesquisador deve seguir a ética em pesquisa e o rigor metodológico para que seja preservada a cientificidade da metodologia da pesquisa-ação ${ }^{(4,11)}$.

Buscando levantar as produções científicas em Enfermagem que utilizaram esta metodologia identificou-se a ausência do título Pesquisa-ação entre os Descritores em Ciências da Saúde (DeCS), cadastrados na Biblioteca Virtual de Saúde (BVS). Isso certamente influencia na difusão deste método de pesquisa, não só na Enfermagem, bem como em todas as áreas das ciências.

Outra limitação para utilização da pesquisa-ação refere-se ao maior investimento de tempo na execução de todas as etapas metodológicas, o que exige a disponibilidade tanto do pesquisador e sua equipe, quanto dos participantes da pesquisa. A produção de dados neste método se dá durante a realização dos seminários programados e planejados de acordo com os objetivos da investigação e sendo imperativa a participação dos envolvidos, não permitindo que seja realizada apenas uma fase, como a diagnóstica. O método tem como finalidade uma ação para a mudança e transformação da realidade do sujeito, portanto necessita ser desenvolvido em sua integralidade ${ }^{(9)}$.

\section{CONSIDERAÇÕES FINAIS}

A pesquisa-ação dentre as várias abordagens metodológicas que podem ser utilizadas para a realização de pesquisas em Enfermagem destaca-se por objetivar a transformação de uma realidade através de uma ação planejada, a inserção do pesquisador no campo de coleta de dados, a interação entre o pesquisador e o participante, além da colaboração dos participantes como agentes transformadores de sua realidade, capazes de modificarem suas práticas através do seu aprendizado.

Desta forma, esta metodologia mostra-se aplicável na área da Enfermagem, considerando que a pratica profissional exige características do enfermeiro pesquisador, que facilitam a utilização deste método de pesquisa, dentre as quais se destacam o saber escutar, prestar atenção aos seus clientes, ser sensível aos problemas da comunidade que trabalha e aos seus sentimentos, além de ser íntegro e principalmente ético como profissional e em suas pesquisas.

Este método permite uma interação entre o pesquisador e o pesquisado, relação esta que já é estabelecida na prática cotidiana das atividades desenvolvidas pelo enfermeiro, visto que o mesmo permite que os sujeitos (clientes) tenham voz e vez, ou seja, permite um diálogo aberto, participativo e reflexivo, assistindo-o de forma holística, incluindo-o sempre em um conjunto com sua família e comunidade, além de buscar constantemente a transformação positiva dessa realidade.

\section{REFERÊNCIAS}

1. Minayo MCS. O desafio do conhecimento: pesquisa qualitativa em saúde. $11^{\text {a }}$ ed. São Paulo: Hucitec; 2008.

2. Lobiondo-Wood G, Haber J. Pesquisa em enfermagem: métodos, avaliação crítica e utilização. $4^{\mathrm{a}}$ ed. Rio de Janeiro: Guanabara-Koogan; 2001.

3. Franco MAS. Pedagogia da pesquisa-ação. Educação e Pesquisa 2005; 31(3): 483-502.

4. Gritten L, Méier MJ, Zagonel IPS. Pesquisa-ação: uma alternativa metodológica para pesquisa em enfermagem. Texto Contexto Enferm 2008; 17(4): 765-770.

5. Thiollent M. Metodologia da pesquisa-ação. $16^{a}$ ed. São Paulo: Cortez; 2008.

6. Figueiredo MLF. A mulher idosa e a educação em saúde: saberes e práticas para promoção do envelhecimento saudável [tese]. Rio de Janeiro (RJ): Escola de Enfermagem Anna Nery, Universidade Federal do Rio de Janeiro; 2005.
7. Andrade JS de, Vieira MJ. Prática assistencial de enfermagem: problemas, erspectivas e necessidades de sistematização. Rev Bras Enferm 2005; 58(3): 261-5.

8. Santos AMR, Reichert APS, Nunes BMVT, Morais SCRV, Oliveira ADS, Magalhães RLB. Construção coletiva de mudança no Curso de Graduação em Enfermagem: um desafio. Rev Bras Enferm 2007; 60(4): 410-415.

9. Sommer R, Amick T. Pesquisa-ação: ligando pesquisa a mudança organizacional. Planejamento de Pesquisas nas Ciências Sociais Brasília. 1984. [Citado em: 3 abril 2009]. Disponível em: http://www.unb.br/ip/lpa/pdf/04Action.pdf

10. Hoga LAK, Reberte LM. Pesquisa-ação como estratégia para desenvolver grupo de gestantes: a percepção dos participantes. Rev Esc Enferm USP 2007; 41(4): 559-566.

11. Tripp D. Pesquisa-ação: uma introdução metodológica. Educação e Pesquisa 2005; 31(3): 443-6. 